EPJ Web of Conferences 33, 01007 (2012)

DOI: $10.1051 /$ epjconf/20123301007

(C) Owned by the authors, published by EDP Sciences, 2012

\title{
Evaluation of solar thermal storage for base load electricity generation
}

\author{
R. Adinberg ${ }^{\mathrm{a}}$ \\ Weizmann Institute of Science, Solar Energy Research Facilities, 76100 Rehovot, Israel
}

\begin{abstract}
In order to stabilize solar electric power production during the day and prolong the daily operating cycle for several hours in the nighttime, solar thermal power plants have the options of using either or both solar thermal storage and fossil fuel hybridization. The share of solar energy in the annual electricity production capacity of hybrid solar-fossil power plants without energy storage is only about $20 \%$. As it follows from the computer simulations performed for base load electricity demand, a solar annual capacity as high as $70 \%$ can be attained by use of a reasonably large thermal storage capacity of 22 full load operating hours. In this study, the overall power system performance is analyzed with emphasis on energy storage characteristics promoting a high level of sustainability for solar termal electricity production. The basic system parameters, including thermal storage capacity, solar collector size, and annual average daily discharge time, are presented and discussed.
\end{abstract}

\section{Introduction}

The share of solar energy in the annual electricity production capacity of hybrid solar-fossil power plants, which is called an annual solar capacity factor or solar fraction [1,2], can be considered as a primary indicator of the sustainability of solar thermal electricity generation technology. Without thermal energy storage, the capability of hybrid solar-fossil power systems to match typical grid load demands is limited to a solar fraction of about $20 \%$. Therefore, a major part of the energy supply must come from fossil fuels, such as coal, natural gas, oil.

To reduce significantly the fossil fuel dependency of the hybrid power plants by making the most of solar energy, solar power systems should have the ability to accumulate a large amount of solar energy during sunlight hours in order to retrieve the storage when the solar radiation is too low or not available to keep the process running smoothly. To facilitate solar thermal storage, the solar collector area of a solar power system must be enlarged so that part of the available solar power can be used to charge the thermal storage simultaneously with operating the power block, whenever the solar flux is sufficiently high, i.e. over the current load demand.

In the literature, the feasibility of replacing fossil fuels with thermal storage in backing solar operating cycles has not yet been assessed to the greatest potential extent. As it follows from the simulation analysis performed over an annual operating cycle [3], a pure solar thermal process, for which the solar fraction is $100 \%$, requires an absolutely unrealistic storage capacity value greater than a thousand full load operating hours. With the current state of the art in the thermal storage

\footnotetext{
a e-mail : roman.adinberg@weizmann.ac.il
}

This is an Open Access article distributed under the terms of the Creative Commons Attribution License 2.0, which permits unrestricted use, distribution, and reproduction in any medium, provided the original work is properly cited. 
design, e.g. 2-tank molten salt system [4], which has potential for supplying about 10 full load operating hours to large-scale (several tens of MWe) parabolic through solar power plants, the solar fraction was estimated a maximum of $40 \%$.

The objective of this work was to conduct analysis of technical means leading to a considerable change in the relationship of quantity between the solar and fossil annual capacities in favor of solar energy, aimed to increase the solar fraction of hybrid solar thermal electrical power plants up to $70 \%$. For this purpose, the mathematical-statistical model of yearlong solar operating cycles developed in [3] is applied to simulate the effects of thermal storage capacity and solar collector size on the energy balance of base load power plants.

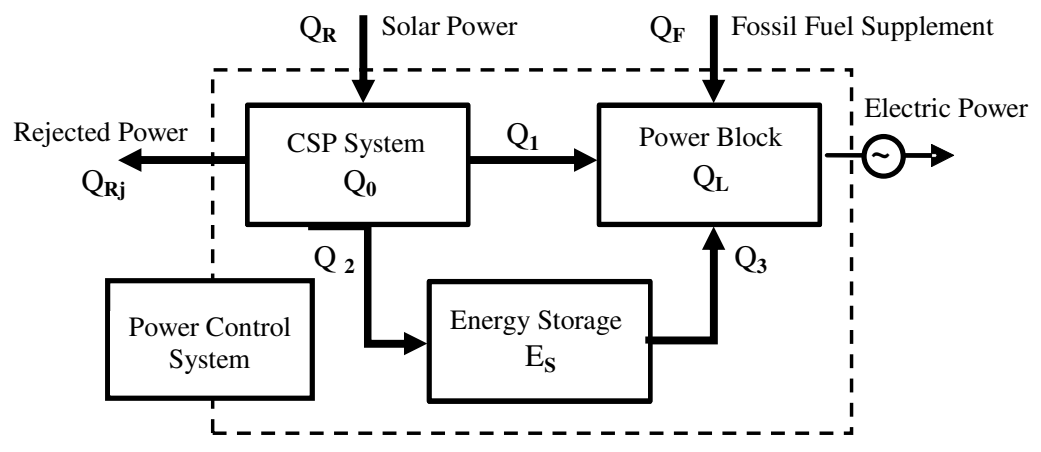

Fig. 1. Block diagram of a solar thermal electric power system.

\section{Model Basics}

Figure 1 represents the conceptual model of solar thermal electric power plants, which consists of the following major components: a CSP (concentrating solar power) system (particularly, a parabolic trough solar collector), a thermal energy storage facility (in general, a well-insulated tank containing the thermal storage material), a power block (i.e. the Rankine cycle including a fossil fuel backup system), and a power control system.

The control system logic that constitutes the basic core of the model is depicted in Table 1 . Primarily, the CSP system converts the incident solar power $Q_{R}$ (direct normal irradiance - DNI) into the thermal power $Q_{0}$ of the high-temperature heat transfer fluid (HTF: e.g. $300-400^{\circ} \mathrm{C}$, thermal oil). Then, the available power is distributed by the HTF flow between the power block, $Q_{l}$, and the thermal storage, $Q_{2}$. Simultaneously, some amount of power, $Q_{3}$, can be extracted from the storage and directed to the power block. In addition, fossil-fueled power generation, $Q_{F}$, might be required in order to operate the power block at a specified load level, $Q_{L}$. When excess amount of solar energy occurs due to the storage capacity limit, most likely in the summer months, it is rejected by the system, $Q_{R j}>0$.

Table 2 presents the modeling method developed, where equation (1) describes the conversion of DNI into the CSP output $Q_{0}$ by means of the efficiency factor $\varkappa$. The energy balance equations (2) and (3) are used to control the power flow through a solar power plant at every instant of operating time. Solar fraction $\alpha$, which is expressed in the integral form (4), gives the contribution of solar energy in the continuous generation of power over an annual operating cycle. The parameter $\beta$ in (5) defines the amount of solar energy directly delivered to the power block as part of the total amount of energy provided by the CSP system. It is an analogue of the solar multiple [5], a factor by which the solar field size must be multiplied in order to supply energy for storage in addition to the amount of energy going directly to the power block at nominal conditions. 


\section{$2^{\text {nd }}$ European Energy Conference}

Table 1. Logic operations of the power control system.

\begin{tabular}{|llc|c|c|}
\hline CSP Output & $Q_{0}$ & \multicolumn{2}{c|}{$\geq Q_{\boldsymbol{L}}$} & $<Q_{\boldsymbol{L}}$ \\
\hline Storage charge state & \multicolumn{2}{c|}{ Partial } & Full & (not applicable) \\
\hline Direct power input & $Q_{1}=$ & \multicolumn{2}{c|}{$Q_{L}$} & $Q_{0}$ \\
\hline Storage charge & $Q_{2}=$ & $Q_{0}-Q_{l}$ & 0 & 0 \\
\hline Storage discharge & $Q_{3}=$ & 0 & $Q_{L}-Q_{0}$ \\
\hline Rejected power & $Q_{R j}=$ & 0 & $Q_{0}-Q_{l}$ & 0 \\
\hline Fossil fuel input & $Q_{F}=$ & 0 & $Q_{L}-Q_{l}-Q_{3}$ \\
\hline
\end{tabular}

Table 2. Basic model equations and definitions.

\begin{tabular}{|c|c|c|c|}
\hline Power conversion & $Q_{0}+Q_{R j}=\varkappa Q_{R}$ & $\mathrm{~W} / \mathrm{m}^{2}$ & (1) \\
\hline Power distribution & $Q_{1}+Q_{2}=Q_{0}$ & $\mathrm{~W} / \mathrm{m}^{2}$ & (2) \\
\hline Total balance & $Q_{1}+Q_{3}+Q_{F}=Q_{L}$ & $\mathrm{~W} / \mathrm{m}^{2}$ & (3) \\
\hline Solar fraction, $0<\alpha \leq 100$ & $\alpha=100 \int_{0} Q_{0}(t) d t / \int_{0} Q_{L}(t) d t$ & $\%$ & (4) \\
\hline Solar collector factor, $\beta>1.0$ & $\beta=\int_{0}^{y r} Q_{0}(t) d t / \int_{0}^{y r} Q_{1}(t) d t$ & & (5) \\
\hline Energy content of storage & $E_{S}(t)=\int_{0}^{\imath}\left[Q_{2}(\tau)-Q_{3}(\tau)\right] d \tau, t \leq y r$ & $\mathrm{Wh} / \mathrm{m}^{2}$ & (6) \\
\hline Storage capacity & $\varphi=\operatorname{Max}\left[E_{S}(t)\right] / Q_{L}$ & $\mathrm{~h}$ & (7) \\
\hline Average discharge period & $\theta=24 \int_{0}^{y r} Q_{3}(t) d t /\left(Q_{L} * y r\right)$ & $\mathrm{h}$ & (8) \\
\hline Rejected energy fraction & $e_{r j}=100 \int_{0}^{y r} Q_{R j}(t) d t / \int_{0}^{y r} Q_{0}(t) d t$ & $\%$ & (9) \\
\hline Initial conditions & $E_{S}(0)=E_{S}(y r)=0$ & & (10) \\
\hline Annual operating cycle & $y r=8760$ & $\mathrm{~h}$ & (11) \\
\hline
\end{tabular}

The variable energy content of thermal storage $E_{S}(t)$ is given by the integral equation (6), from which the highest quantity of thermal energy measured during the year is the nominal storage capacity $\varphi(7)$ expressed in full load operating hours. Also, it is supposed (10) that the thermal storage is empty at the beginning and fully utilized at the end of the annual operating cycle.

Numerical statistical computations based on the model algorithm including Tables 1 and 2 were carried out with the aid of the Mathematica program (Version 8.0, Wolfram Research). The input data included a time series of $Q_{R}$ for the years 2004-2006 related to the area in Southern Spain [6] with a total annual DNI value of $2.1 \mathrm{MWh} / \mathrm{m}^{2}$. The solar thermal efficiency factor $x$ was calculated for parabolic trough solar collectors operated on thermal oil as the heat transfer fluid [2, 7]. The electric load demand was set constant 24 hours a day considering the base load operation. All the calculated power and energy variables pertain to one square meter of the solar collector aperture area and have a 1-hour time resolution. 


\section{Simulation results and discussion}

Figure 2(a) presents the dependence of storage capacity $\varphi$ on solar fraction $\alpha$ varied from near 20 (no storage applied, $\varphi=0$ ) to $100 \%$ (the pure solar power cycle), on condition of full utilization of solar energy, so that the rejected power $Q_{R j}=0$ throughout the annual operating cycle. It can be seen that the function $\varphi(\alpha)$ has a marked change next to a point specified by the coordinates $\alpha=50 \%$ and $\varphi$ $=14 \mathrm{~h}$. In the first half $\alpha$-range shown in Figure 2(b), $\varphi(\alpha)$ is rather a linear, relatively low-growing function, in regard to the region of $\alpha>50 \%$, where the storage capacity $\varphi$ increases rapidly to very large values $\varphi>10^{3} \mathrm{~h}$ required for continuous pure solar operation, for which the solar fraction $\alpha$ $=100 \%$.

As already noted, solar fraction values $\alpha<40 \%$ are relevant to the current thermal storage systems utilizing either sensible or latent heat of molten salts or various other storage materials [8]. The relatively low energy density of available thermal storage materials limits designing of storage systems for large-scale power plants (50 MW electrical power capacity and more) to below $\varphi=10$ full load operating hours due to a very large amount of storage materials needed to fill the storage tanks.

Another important attribute of thermal storage is the discharge period $\theta$ that can be expressed, by analogy with the storage capacity $\varphi$, in full load operating hours (8). Parameter $\theta$, as an annual average value of storage energy, is always considerably less than $\varphi$, the maximum energy content of the storage, especially in the region of $\alpha>50 \%$. The ratio $\theta / \varphi$ is near 0.5 at $\alpha=50 \%$ and it drops as low as about 0.01 at $\alpha=100 \%$. This provides clear evidence of large storage energy variations on daily and seasonal time scales across an annual operating cycle.

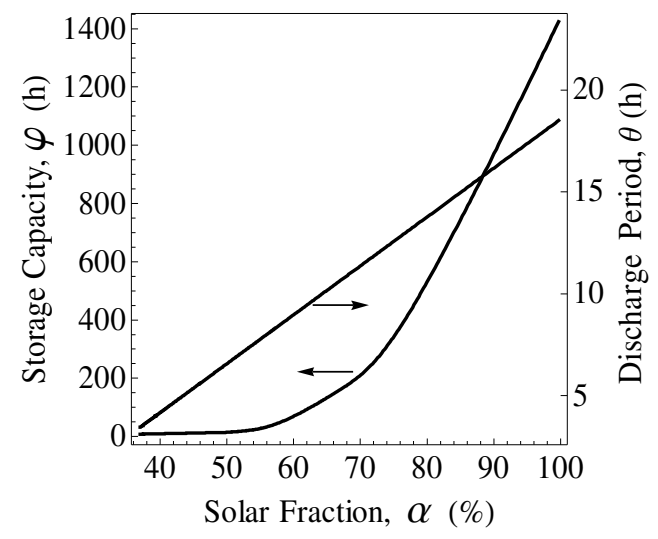

(a)

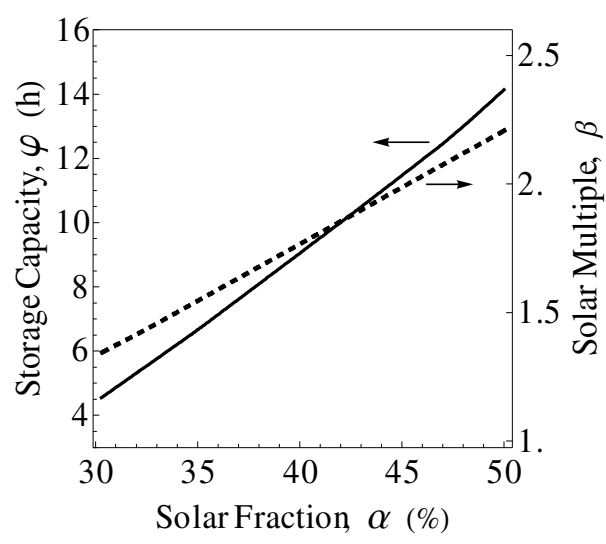

(b)

Fig. 2. Storage capacity $\varphi$, average discharge period $\theta$, and solar collector factor $\beta$ (dashed line) as functions of solar fraction $\alpha$ for a hybrid power parabolic trough plant, showing the full (a) and the first half (b) $\alpha$-range.

As is also shown in Figure 2 (dashed lines), the solar collector factor (solar multiple) $\beta$ for hybrid solar power systems including thermal storage is linearly related to the solar fraction $\alpha$. Within the whole range of solar fraction variation, $20<\alpha \leq 100 \%$, the corresponding increase of $\beta$ is from 1.0 to 4.4 . 


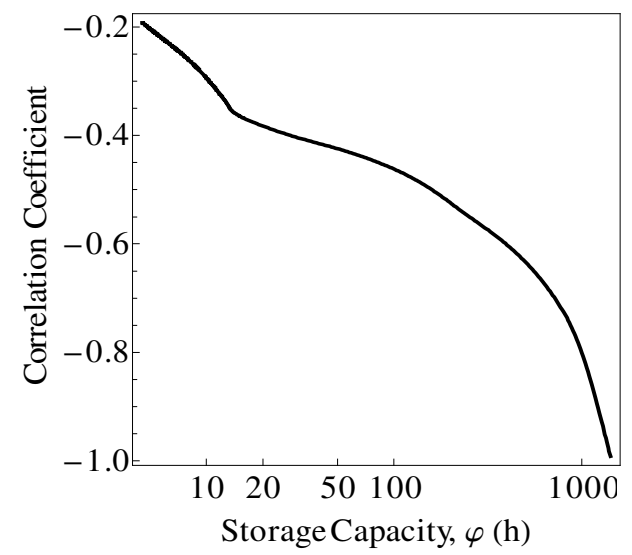

Fig. 3. Pearson's corrélation coefficient between direct power input $Q_{1}$ and storage discharge power $Q_{3}$ as a function of storage capacity $\varphi$.

The effect of storage capacity on the performance of a solar power system is illustrated in Figure 3 by a correlation between the power variables $Q_{1}$ and $Q_{3}$. Naturally, the correlation coefficient is negative because according to Eq. (3) as either one of the variables, e.g. $Q_{1}$, decreases the other, $Q_{3}$, increases, and vice versa. This graph shows that the correlation coefficient varies from -0.2 for hybrid systems with a small storage capacity of 4 full load operating hours to a value of -1 referring to the pure solar systems, which are fully supported by thermal storage, without any use of fossil fuels. Since the operating solar hybrid power systems are provided with thermal storage capacities below $\varphi=10 \mathrm{~h}$, they are characterized by very low values of the correlation coefficient -0.2 to -0.3 due to the short-term capability of the storage to support the solar-powered process. The last fact follows from the discharge period values $\theta<5 \mathrm{~h}$ shown in Figure 2.

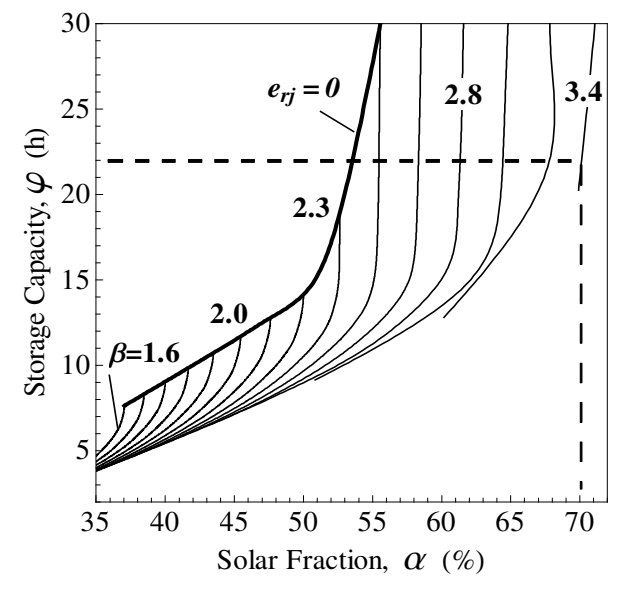

(a)

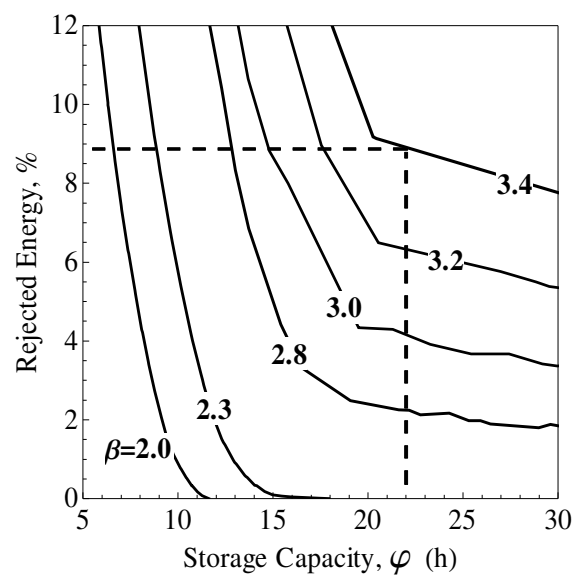

(b)

Fig. 4. The changes of storage capacity $\varphi$ (a) and rejected energy $e_{r j}$ (b) with the solar collector factor $\beta$. In graph (a), the most left curve, marked as " $e_{r j}=0$ ", is as same as that in Figure 2 (a). 


\section{A high solar fraction power system}

It is important to investigate the potential of expanding the solar fraction of hybrid power systems substantially over $40 \%$ to make solar power a dominant source of electricity in sun-rich regions of the world. Two methods of attaining a solar fraction $\alpha=70 \%$ can be considered:

1. One straightforward approach is to choose the respective value of storage capacity from Figure 2 , which is $\varphi \approx 200 \mathrm{~h}$ and the required solar collector factor $\beta \approx 3$. However, it is absolutely clear that in view of the present state of the thermal storage technology such a long-term energy capacity cannot be made available for commercial-scale solar power systems.

2. The other method is essentially based on deviation from the system energy balance by setting an increased value of the solar collector factor $\beta$. The larger solar field has the advantage of providing additional amount of solar energy in the winter season, when solar power conditions are often inadequate to fully charge the storage during sunlight hours of a day. However, this method inevitably leads to some amount of solar energy rejected by the system, $e_{r j}>0$, that might occur when the storage is fully charged, definitely in the summer months.

Figure 4 demonstrates the effect of solar collector factor $\beta$ on the system parameters of a base load power plant within a moderate range of storage capacities, $\varphi \leq 30 \mathrm{~h}$. It is seen, for example, choosing a storage capacity $\varphi=22 \mathrm{~h}$ (graph (a), dashed lines), that changing from $\beta=2.4$, for which $e_{r j}=0$, to 3.4 causes an increase in solar fraction from 53 to $70 \%$, respectively. In this case (graph (b), dashed lines), some of the total annual amount of solar energy is rejected, $e_{r j}=9 \%$, (could be utilized as an auxiliary heat source for covering the plant's needs).

As follows from graph (b), the favorable conditions for altering the parameter $\beta$ are found below approximately $10 \%$ of the rejected energy, where the ascent of the $\varphi$-curves is rather low as compared with that in the upper part of the diagram. According to graph (a), the higher the storage capacity, the stronger is the impact of the solar collector factor, resulting in a larger solar fraction increment for a power plant.

Table 3. Comparison of the basic parameters evaluated for a conventional solar power plant (similar to the 50-MWe Andasol-1 parabolic trough power plant in Spain [9]) and the virtual high solar fraction system.

\begin{tabular}{|c|c|c|c|c|c|}
\hline $\begin{array}{c}\text { Solar power } \\
\text { plant }\end{array}$ & $\begin{array}{c}\text { Storage } \\
\text { capacity } \\
\varphi(\mathrm{h})\end{array}$ & $\begin{array}{c}\text { Solar } \\
\text { collector } \\
\text { factor } \beta\end{array}$ & $\begin{array}{c}\text { Solar } \\
\text { fraction } \\
\alpha(\%)\end{array}$ & $\begin{array}{c}\text { Discharge } \\
\text { period } \\
\theta(\mathrm{h})\end{array}$ & $\begin{array}{c}\text { Rejected } \\
\text { energy } \\
e_{r j}(\%)\end{array}$ \\
\hline Conventional & 7.5 & 1.6 & 37 & 3.3 & 0 \\
\hline Virtual & 22 & 3.4 & 70 & 11.5 & 9 \\
\hline
\end{tabular}

The results of Table 3 suggest that a conventional solar power plant, $\alpha=35-40 \%$, can virtually be transformed into a high solar fraction power plant, $\alpha=70 \%$, by means of increasing the solar collector size by a factor about 2 and the storage capacity by a factor about 3 , without need to change the power block size. The expected economic benefit is based on the significant reduction, by about a half (from 60 to $30 \%$ ), of the fossil fuel supplement for solar thermal electricity generation. 


\section{Conclusions}

Solar thermal storage and fossil fuel hybridization are used to stabilize power delivery and prolong daily operating cycle of solar thermal power plants. The annual solar fraction of commercial-scale hybrid power plants employing thermal storage with a nominal capacity within 10 full load operating hours is limited to below about $40 \%$, so that most of the energy input must be provided by burning fossil fuels. The simulation results of this study show that an improved solar thermal power plant efficiency resulting in a solar fraction of $70 \%$ can be achieved by moderate enlargement of the solar field and thermal storage, with no need to change the power block size. Herewith, some few percent of the annual amount of solar energy collected can be redirected for auxiliary use.

\section{Acknowledgement}

This research was sponsored by the FP7 European Research Infrastructures Project - SFERA: Solar Facilities for the European Research Area (http://sfera.sollab.eu/).

\section{References}

1. B.C. Staley, J. Goodward, C. Rigdon, A. MacBride, Juice from concentrate: Reducing emissions with concentrating solar thermal power. The World Resources Institute (WRI, 2009), http://www.wri.org/publication/juice-from-concentrate.

2. H. Price, A parabolic trough solar power plant simulation model, NREL/CP-550-33209, National Renewable Energy Laboratory, Cole Boulevard, Golden, Co. (2003).

3. R. Adinberg, Simulation analysis of thermal storage for concentrating solar power. Applied Thermal Engineering 31, 3588 (2011).

4. M. Medrano, A. Gil, I. Martorell, X. Potau, L. F. Cabeza, State of the art on high-temperature thermal energy storage for power generation. Part 2-Case studies. Renewable and Sustainable Energy Reviews 14, $56(2010)$.

5. M.J. Montes, A. Abanades, J.M. Martinez-Val, M. Valdes, Solar multiple optimization for a solar-only thermal power plant, using oil as heat transfer fluid in the parabolic trough collectors. Solar Energy 83, 2165 (2009).

6. Solar Radiation Series of Data, http://www.soda-is.com/eng/services/index.html.

7. V. Quaschning, Technical and economical system comparison of photovoltaic and concentrating solar thermal power systems depending on annual global irradiation. Solar Energy 77, 171 (2004).

8. M. Liu, W. Saman, F. Bruno, Review on storage materials and thermal performance enhancement techniques for high temperature phase change thermal storage systems. Renewable and Sustainable Energy Reviews 16, 2118 (2012).

9. Solar power and chemical energy systems, SolarPACES Annual Report 2008. M. Geyer (Ed.). Germany, DLR, Koln (2009). 